\title{
Cross-Cultural Practice in International Corporate Governance
}

\author{
Chiu-Yi (Joy) Lee \\ Victoria University, Australia
}

\begin{abstract}
By means of the increasing global competition and internationalization of world markets, international expatriates assignments are more and more essential to successful worldwide development for many multinational corporations. Therefore, international expatriates are imperative to the survival of globe enterprises in the twenty-first century. Expatriates can become an important human resource to international enterprises or multinational operations. To facilitate business expatriates adjust to an overseas environment and work effectively, MNCs need to recognize the demographic factors those to affect cross-cultural adjustment. The main purpose of this study is utilizing Lee's (2002) model to investigate the relationship among the demographic factors and cross-cultural adjustment of Taiwanese expatriates assigned to Mainland. Also, the empirical outcomes were compared between Taiwanese expatriates located in Mainland China and United States.
\end{abstract}

In examining the significant degree of Taiwanese expatriates assigned to Mainland China, the instrument was a questionnaire survey conducted to this study. The variables of interest were measured using items Likert-type of questions, and those items are divided into seven categories. Data collected from 353 participants who have experience of post to Mainland China for international assignments. Descriptive statistics, ANOVA and T-test were employed to analyse data.

The statistical results of this study were compared Lee's (2002) research that associated with Taiwanese banking expatriates in United States. This thesis concludes with suggestions for both international enterprises or MNCs and individual expatriate who operate overseas journey in their normal path of business.

\section{Introduction}

In the current climate of rapid globalization, expatriation has been an important element of international business operations. Expatriates are able to play tremendously significant roles during worldwide assignments. Much of the expatriate management literature has focused on the management of crosscultural adjustment (eg. Harris and Moran 1989; Black and Gregerson 1991). This focus seems justifiable when the high cost of expatriate failure, attributed to inability to adjust (Adler 1986), is considered. Expatriates are viewed to have 'failed' in their overseas assignment if they return to the

Copyright (C) 2006 Victoria University. This document has been published as part of the Journal of Business Systems, Governance and Ethics in both online and print formats. Educational and non-profit institutions are granted a nonexclusive licence to utilise this document in whole or in part for personal or classroom use without fee, provided that correct attribution and citation are made and this copyright statement is reproduced. Any other usage is prohibited without the express permission of the parent company prematurely. Since 1987 an open policy under the Chinese government has allowed more investment to flow into Mainland China from Taiwan, to the benefit of both countries. At the same time, Taiwan's government deregulated control over foreign exchange and this led to a rapid increase in outward investment by Taiwan's enterprises. Economic relations between Taiwan and China have developed 
rapidly. Further, following the increasing investment more and more Taiwanese enter Mainland China for business and travel (ICMEA, 2001). According to the China Travel Yearbook and the China Monthly Statistics, the number of Taiwan tourists to Mainland China during the year of 2004 totalled 3.69 million, an increase of $34.9 \%$ as compared to the same period of the previous year. Cumulative figures from 1988 to the end of December 2004 showed that 33.88 million persons travelled to Mainland China.

While organizations may perceive expatriation as an attractive method for accumulating foreign markets, they face the challenges of management of the most appropriate individuals. Thus factor contributing to the successful expatriation experience are significant to multinational corporations (MNCs). The aims of the project are: to examine the influence of demographic factors on the crosscultural adjustment of Taiwanese managers stationed in Mainland China. This study result may assist Taiwan enterprises to operate their business efficiently in Mainland China. Also, in order to comprehend whether the demographic factors on cross-cultural adjustment apply to the entire expatriate community, the results of this study will be compared with Lee's (2002) research that related to Taiwanese expatriates located in United States.

\section{Literature Review}

\section{Demographic Factors}

According to Brett and Stroh (1995) demographic factors that affect expatriates adjustment include age, educational background, expatriation duration, gender, previous study, previous experience, previous training, marital status, and spouse.

\section{Age}

Age is a critical personal characteristic in Asian societies (Fang 1999; Worm 1997). Respect for old age is particularly emphasized by Confucianism, highlighting the building of a great character through lifelong learning and self-cultivation. Traditionally, young people in Chinese society are not considered dependable, experienced or capable of doing good business (Chan 1963). Even in Western societies, growing older may be associated with increasing maturity (Heckhausen and Krueger 1993; Van Lange et al. 1997).

\section{Individual Ability}

Many researchers have investigated the skills necessary for an executive to be effective in a crosscultural setting (Brein and David 1971; Church, 1982; Mendenhall and Oddou 1985; Stening 1979). Bhagat and Prien (1996) have also set out several factors that affect the success of international assignments. They include individual, family and job-specific attributes as well as the host country cultural environment. Each of these corresponds with categories indicated by Tung (1981) and Hays (1971). In this study, adopt individual educational background to investigate individual ability on crosscultural adjustment.

\section{Expatriation Duration}

Researchers such as Pinder and Schroeder (1987) suggested that the duration of stay in a host country has implications for relocated individuals to become efficient in their assigned job. Consequently, an hypothesis underlying the length of stay in a host country is that the longer they reside in a host country, the more familiar expatriates become with their jobs and working conditions, and as they become more familiar, the better their performance will become (Black 1988; Kawes and Kealey 1981). In addition, Nagai (1996) recommended that the length of stay in a host country be supposed to be a significant factor relating to successful performance. 


\section{Gender}

Previous research (Anderson, Milkovich and Tsui 1981; Markham, Macken, Bonjean and Corder 1983; Markham and Pleck 1986) demonstrated that there is a tendency toward female employees being less willing to take over expatriate assignment, and the gender of employee has mainly exposed a constant standard of relationships for domestic transfer. On the other hand, a study of international transfer by Brett and Stroh (1995) indicated that there has not been a significant connection between employee gender and willingness to transfer. Moreover, contrary to the traditional prevalent corporate viewpoint and practice, results of the study by Westwood and Leung (1994) suggest that, in terms of disposition, women may often be better suited for expatriate assignments than men.

\section{Previous Overseas Experience}

Past foreign experience affects how confident an expatriate will feel in a new country, and is positively related to success in a global assignment (Bochner et al. 1986, Bochner et. al. 1971; Brein and David 1971; Church 1982; Searle and Ward 1990). Previous international experience has been recommended as a significant factor in employee adjustment during international assignments, as well as an attribute related to willingness to adopt overseas assignments. Church (1982) and Stening (1979) reported that if the previous experiences were work-related, they would facilitate the construction of precise work expectations. In contrast, if the previous experiences were not work-related, for example, previous experiences concerning study overseas, they would facilitate the construction of non-work expectations.

\section{Marital Status}

Researchers into domestic transfer of workplace and international transfers normally agree with the concept that single individuals have a higher willingness to transfer to international assignments than married individuals (Brett, Stroh and Reilly 1990). Married individuals perhaps must consider various family issues, such as the effect of children and family members on international mobility that is more fundamental anxiety than marital status.

\section{Family Issues}

The adjustment of the expatriate's spouse and family toward the foreign move is one of the most critical determinates of whether an expatriate completes his or her assignment (Black and Gregersen, 1991; Tung, 1981).

\section{Dual Assignment}

Researchers estimate that between 16 and 40 percent of all American expatriates do not complete their assignments (Mendenhall, Dunbar and Oddou 1987; Mendenhall and Oddou 1988; Wederspahn 1992; Dowling, Schuler and Welch 1994). This percentage maybe expected to escalate in the near future due to the projected increase in female expatriates and dual-career couples (Harvey 1996, 1997a, 1997b).

\section{Cross-cultural Adjustment}

Cross-cultural adjustment is generally defined as the process of adaptation to living and working in a foreign culture. It is the perceived degree of psychological comfort and familiarity a person has with the new host culture (Black 1988; Mendenhall and Oddou 1987). Several researchers have highlighted factors affecting the process of adjustment. For example, Black, Mendenhall and Oddou (1991) identified anticipatory (before-leaving) and in-country (post-arrival) factors. In addition, they noted work, interactions and general adjustment as three levels of adjustment. Feldman and Tompson (1992) identified six sets of factors: demographic variables; the extent of 'internationalness' of the job change; job characteristics variables; amount of organization support vis a vis assistance and career development; degree of difference between successive job assignments; and types of individual coping strategies. It is possible to classify factors affecting cross-cultural adjustment into two broad types; extrinsic (those relating to the organization and environment) and intrinsic factors (those relating to the characteristics, psychological and physical, of the individual. Many studies have found that the crucial problem for the expatriate is that adaptation to the unfamiliar culture than with their professional expertise (eg. Aahad and Osman-Gani, 2000; Dowling et al., 1999; McEnery and DesHarnais, 1990; 
Osland, 1995). Successful adaptation and cultural adjustment not only directly influence expatriates performance but also lead to corporate success in the international stage.

\section{Taiwanese Outward Investment in Mainland China}

Since Mainland China started its economic reform and adopted an open-door policy in 1978 it has promoted foreign trade and welcomed foreign investment. Economic relations between Taiwan and Mainland China have developed very rapidly, due to strong business motivations in both societies. In the late 1980s Taiwanese outward investment mainly focused on the United States and the member countries of the Association of South East Asian Nations (Philippines, Indonesia, Thailand, Malaysia, and Vietnam). However, Mainland China became the principal country of Taiwanese Foreign Direct Investment (FDI) from 1990s.

According to Taiwan Economic Statistical Data Book in 2004 shown that Taiwanese approved outward foreign direct investment in Asian countries, which was $24.25 \%$ of total FDI and total amount of investment cases was 7981 cases from 1994 to 2004, and cases of approved outward investment in Asian countries was 1937(24.27\%) cases from 1994 to 2003. By contrast, Taiwan's approved foreign direct investment (FDI) and indirect in Mainland China, which now accounts for roughly $51.98 \%$ of its total direct and indirect investment in Mainland China from 1994 to 2004, and total amount of cases was 29875 from 1994 to 2003, continues on an increasing trend. The total number of cases invested in Mainland China was fifteen times higher than the total number of cases invested in ASEAN from 1994 to 2003 .

\section{Conceptual Framework}

The purpose of this research is to examine the relationship among the independent variables demographic factors and the dependent variable as cross-cultural adjustment.

The research question is: Do demographic factors (as age, gender, expatriate duration, marital status, dual assignment, and family experience) affect the cross-cultural adjustment of Taiwanese enterprises' expatriates in Mainland China?

\section{Methodology}

This research utilized quantitative methods. The questionnaire began with individual background variables: age, educational level, expatriation duration, gender, previous study, previous experience, previous training, marital status, whether accompanied by and spouse employment situation. In all cases the respondents were asked to select the relevant option among classified response alternatives.

\section{The Research Sample}

The target population of this study is 1,786 Taiwanese manufacturing firms located in Shanghai. Shanghai is the most developed city of east China and many Taiwanese investors set up their manufacturing company in here. This study used a stratified sampling procedure based on type of industry to select the sample. There are 20 different categories of industries such as food industry, plastics industry, cement industry, spin and weave, electric machinery, electric equipment and so on included in these 1,786 firms. Twenty companies were selected from each industry by using a random numbers table. Therefore, there a total of 400 firms were selected from the address book that is issued by the Straits Exchange Foundation of Taiwan. Non- responses were managed by replacement. 


\section{Procedure}

Data were collected by means of a mail survey. Prior to sending the questionnaire packages a brief letter was sent to the HR manager, together with an invitation letter, questionnaire and support letter from the Straits Exchange Foundation of Taiwan inviting participation in the pilot study.

\section{Statistics Analysis}

All of statistical data analyses were performed on a PC computer using SPSS (Statistical Package for Social Science) for Windows. The analysis used descriptive statistics, T-tests and ANOVA. Descriptive statistics were used to describe the sample and inferential statistics to draw conclusions about the theoretical model.

\section{Descriptive Statistics}

Descriptive statistics were conducted for demographic factors including age, educational level, expatriation duration, gender, marriage, previous study experience, previous overseas experience, and previous training experience. It also included whether the participants lived with their own family during the overseas assignment and whether the partners of participants had job employment during the overseas assignment.

\section{T-Test}

T-test was run between cross-cultural adjustment and various demographic factors. These factors are gender, previous study experience, previous overseas experience, previous cross-cultural training.

\section{ANOVA}

ANOVA tests of mean (cross-cultural adjustment) difference were conducted for three demographic factors. The demographic factors are educational level, age and expatriation duration.

\section{Research Results}

Total of 1200 questionnaires initially mailed to Taiwanese business expatriates in Shanghai and followed-up by e-mail. Due to the limited time span of the research, mailing the questionnaire to each overseas expatriate and waiting on him or her to mail it back was considered to time consuming, hence, tracing e-mails were sent four weeks later.

Total responses were 353, but there were 22 invalid questionnaires. As a result, total response 353 minus the invalid questionnaires 22 ; therefore, 331 returned surveys were usable. The percentage of valid questionnaires was 27.58 percent.

\section{Age}

The sample consisted of 331 participants, 22 participants (6.6 percent) were under 30 years old. One hundred and forty nine participants (45.0 percent) were between 31 to 35 years old. One hundred and eighteen participants (35.6 percent) were between 36 to 40 years old. Twenty-six participants (7.9 percent) were between 41 to 45 years old, and 16 participants ( 4.8 percent) were over 46 years old.

\section{Educational Level}

There were 37 participants (11.2 percent) who held high school degree and 122 participants (36.9 percent) with TAFE or college certificates, most participants had graduated from university. There were 142 participants (42.9 percent) who held a bachelor's degree, and 30 participants (9.1 percent) who held postgraduate degrees. 


\section{Expatriation Duration}

Responses indicated that 50 participants (15.1 percent) had been located in Shanghai less than 1 year. One hundred and twenty participants (36.3 percent) had been there for 1 to 3 years and 98 participants (29.6 percent) had been to Shanghai 4 to 5 years. Fifty-six participants (16.9 percent) had been in Shanghai 6 to 10 years, and 7 participants ( 2.1 percent) have been to Shanghai more than 10 years.

\section{Gender}

The number of female participants accounted for only 23 participants (6.9 percent) of total sample (331), while the number of male participants was up to 308 participants (93.1 percent). Taiwanese male expatriates greatly outnumbered female expatriates located in Shanghai.

\section{Overseas Study Experience}

There were 49 participants (14.8 percent) who had obtained their degrees while overseas, while 282 participants $(85.2$ percent) had not.

\section{Previous Overseas Experience}

There were 279 participants ( 84.3 percent) who had never had overseas experience, while 52 participants (15.7 percent) had had overseas experience.

\section{Previous Cross-Cultural Training}

There were 99 participants (29.9 percent) who had had previous cross-cultural training before being posted to Shanghai for their international assignments, but 232 participants (70.1 percent) had never had previous cross-cultural training.

\section{Marital Status}

There were 95 participants ( 28.7 percent) who were single, 232 participants (70.1 percent) who were married, and 4 participants (1.2 percent) who were de facto. Spouse's Living Status

There were 128 participants (38.7 percent) who had their spouse living with them during the overseas assignment, while 203 participants (61.3 percent) did not have their spouse accompanying them.

\section{Partner Employment}

There were 50 participants (15.1 percent) whose spouse had also received an overseas assignment, while 281 participants ( 84.9 percent) had spouses who did not.

Individual factors may perhaps result in expatriates experiencing different degree of cross-cultural adjustment owing to the effect of different emotional status and physical reactions, and they may learn different things from the experiences. This section discusses how individuals factors: age, educational levels, expatriation duration, gender, overseas study experience, previous overseas experience, previous cross-cultural training, and marital status of Taiwanese expatriates as well as partner-employment situation impact on cross-cultural adjustment (Table 6.1).

Table 6.1: The Significance of the Relationship of Each Demographic Factor to Adjust in Mainland China

\begin{tabular}{|l|c|}
\hline \multicolumn{2}{|c|}{$\begin{array}{c}\text { The Significance of the Relationship of Each Demographic Factor to Adjust } \\
\text { in Mainland China }\end{array}$} \\
\hline & Mainland China \\
\hline Age & Significant \\
\hline Educational Levels & Significant \\
\hline Expatriation Duration & Significant \\
\hline Gender & Not significant \\
\hline Overseas Study Experience & Significant \\
\hline Previous Overseas Experience & Significant \\
\hline Previous Cross-cultural training & Significant \\
\hline
\end{tabular}




\begin{tabular}{|l|l|}
\hline Marital Status & Significant \\
\hline Partner Living With Status & Significant \\
\hline Partner Employed Situation & Significant \\
\hline
\end{tabular}

This section considered the reaction on cross-cultural adjustment of attributes of individual Taiwanese expatriates: age, educational level, expatriation duration, gender, overseas study experience, previous overseas experience, previous cross-cultural training, martial status and the employment situation of the partner. According to the summarized result as table of above demonstrates that differences in almost every individual factor significantly affected the cross-cultural adjustment of Taiwanese expatriates who were assigned to Mainland China. The only exception was gender section. Straightforwardly, the crosscultural adjustment of Taiwanese expatriates assigned in Mainland China only unaffected by gender factor, the others factors certainly affect the cross-cultural adjustment of Taiwanese expatriates assigned to Mainland China.

\section{Discussion}

The results of this study were also compared with Lee's (2002) research shown in Table 7.1. Results were quite different between Taiwanese located in the United State and Mainland China. Each signal factor is precisely clarified in the following section.

Table 7.1: The Significance of the Relationship of Each Demographic Factor to Adjust in Mainland China and the United States

\begin{tabular}{|l|l|l|}
\hline \multicolumn{3}{|l|}{ The Significance of Factors Adjust in Mainland China and U.S. } \\
\hline & Mainland China & United States * \\
\hline Age & Significant & Not-significant \\
\hline Educational Levels & Significant & Not significant \\
\hline Expatriation Duration & Significant & Not significant \\
\hline Gender & Not significant & Not significant \\
\hline Overseas Study Experience & Significant & Not significant \\
\hline Previous Overseas Experience & Significant & Not significant \\
\hline Previous Cross-cultural training & Significant & Not significant \\
\hline Marital Status & Significant & \\
\hline Partner Living With Status & Significant & Not significant \\
\hline Partner Employed Situation & Significant & Not significant \\
\hline
\end{tabular}

Source: Lee, H.W. 2002, 'A study of Taiwanese banking expatriates in the United States', Published dissertation of University of Idaho

\section{Age}

Taiwanese expatriates in the age range from 31 to 35 were extensively post to Mainland China. In addition, according to the statistical results presented there was a significant difference between different age levels on cross-cultural adjustment. Comparison with Lee's (2002) research is shows a difference between Taiwanese located in the United State and in Mainland China. The age section of Lee's (2002) results indicated that almost half $(n=26,49.1 \%)$ of participants were from 41 to 45 and $39.6 \%$ participants over 45 . Clearly, Taiwanese expatriates assigned to the United States were largely aged over 40 years old. There was no significant difference between different age levels on crosscultural adjustments. 
As a result, it is clear that age is an important factor for Taiwanese expatriates located in Mainland China, because different age groups demonstrate different degrees of cross-cultural adjustments. However, age was not a significant factor affecting cross-cultural adjustment of Taiwanese expatriates placed in the United States.

\section{Educational Levels}

Based on the ANOVA statistical analysis the result was that there were significant difference between different educational levels on cross-cultural adjustment in this study, and 142 (42.9\%) participants had graduated from university. This was an interesting finding. The results showed that Taiwanese expatriates located in Mainland China who held different level of educational qualification showed different degrees of adjustment to their overseas placement. By contrast, Lee's (2002) research revealed that 35 participants $(66 \%)$ held graduate degrees, and none of the participants had an educational level of junior college or lower, but there was no significant difference between different educational levels on cross-cultural adjustment.

\section{Expatriation Duration}

According to statistical analysis there was a significant difference between different periods of expatriation duration on cross-cultural adjustment. The majority participants had 1 to 3 years $(36.3 \%)$ experience, and 4 to 5 years (29.6\%) experience in this study. As a result, an essential assumption about the duration of stay in a host country is that the longer expatriates stay in a host country, the more familiar expatriates become with their jobs and working conditions, and as they become more familiar, the better their performance will be. However, Taiwanese expatriates post in the United States had diverse opinions as most participants had less than 1 year (22.6\%), and 1 to 3 years (35.8\%). Moreover, there was no significant difference between different expatriation durations on cross-cultural adjustment for Taiwanese expatriates placed in the United States.

\section{Gender}

There were 308 male participants assigned to Mainland China and only $23(6.9 \%)$ female expatriates in this study. Lee's (2002) gender results revealed just 15\% female expatriates located in the United States as well.

The T-test analysis performed to evaluate the cross-cultural adjustment of male expatriates as opposed to female expatriates, revealed that there was no significant difference between males and females on cross-cultural adjustment in this study. Lee's (2002) research confirmed this finding.

\section{Overseas Study Experience and Previous Overseas Experience}

This study demonstrates that previous international experience is positive factor for expatriate adjustment. The test result showed there was a positive relationship between obtaining an overseas degree and cross-cultural adjustment. Conversely, Lee's (2002) published research revealed that there was no significant difference between obtaining a degree in the United States and not obtaining a degree in the United States on cross-cultural adjustment. There was also no significant difference between having had overseas experience and not having had overseas experience on cross-cultural adjustment for Taiwanese expatriates located in United States. As a result, overseas experience, both study experience and work experience, were crucial factors influencing cross-cultural adjustment for Taiwanese expatriates located in Mainland China, but not for the United States.

\section{Previous Cross-cultural Training}

According to the results of the T-test in this study there was a significant difference between expatriates having previous cross-cultural training and not having previous cross-cultural training on cross-cultural adjustment in this study. Although only 29.9 percent of participants receive a cross-cultural training from their enterprises before taking up their overseas assignments this does not mean that cross-cultural training is not necessary for Taiwanese expatriates assigned to Mainland China. In contrast, Lee's (2002) research revealed almost half $(49.1 \%)$ of the participants had previous cross-cultural training, but the other half $(50.9 \%)$ of the participants did not. Interestingly, there was no significant difference 
between having had previous cross-cultural training and not having had previous cross-cultural training on cross-cultural adjustment for Taiwanese expatriates posted to the United States.

\section{Marital Status and Partner Living Status}

In this study, descriptive statistical analysis revealed that $70.1 \%$ of Taiwanese expatriates were married ANOVA statistical analysis revealed that there was a significant difference between different marital status on cross-cultural adjustment. Of the respondents 38.7\% Taiwanese expatriates had their spouse living with them, and T-test statistical analysis revealed that there was a significant difference between living with spouse or partner and not living with spouse or partner during overseas assignment on crosscultural adjustment. Lee's (2002) research related to Taiwanese banking expatriates in the United States revealed in the marital status section that all of the participants were married. It is therefore difficult to analyse the marital status factor affected the cross-cultural adjustment of Taiwanese expatriates located in the United States. Contrary to the present study, Lee's (2002) research demonstrated that there was no significant difference between living with a spouse and not living with a spouse on cross-cultural adjustment. Accordingly, marital status and living with spouse or partner were important factors influencing on cross-cultural adjustment for Taiwanese expatriates located in Mainland China, but not for Taiwanese expatriates placed in the United States.

\section{Partner Employment Situation}

According to the statistic results indicated that there was a positive relationship between working with spouse or partner during the overseas assignment and cross-cultural adjustment in this study. Nevertheless, Lee's (2002) research demonstrated that there was no significant difference between working with spouse and not working with spouse on cross-cultural adjustment. The result in dual employment is in opposition to that of this study. Hence, dual employment was an essential factor to affecting cross-cultural adjustment for Taiwanese expatriates located in Mainland China, but not for Taiwanese expatriates placed in the United States.

\section{Conclusion}

Several individual-level factors are believed to influence cross-cultural adjustment. In this study, the questionnaire began with individual background variables: age, educational level, expatriation duration, gender, previous overseas study, previous overseas experience, previous training, marital status, spouse living with status and spouse employment situation. In all cases the respondents were asked to select the relevant option among classified response alternatives. Each individual factor was significant for different levels of cross-cultural adjustment of Taiwanese expatriates assigned to Mainland China, exclusive of gender. However, Lee's (2002) research revealed that whole individual factors were not significant different on cross-cultural adjustment of Taiwanese expatriates posted to United States, but not included the marital status due to all of Taiwanese expatriates located in the United States married. It was therefore difficult to recognize a difference in cross-cultural adjustment between married and unmarried expatriates. Consequently, from the compared result that is not difficult to figure out there is a reappearance of interest in the experiences of people who work in other cultures. International organizations should put more attention on the procedure of selection expatriates and previous training before assign expatriates to perform their global assignments.

\section{Bibliography}

Aahad, M. and Osman-Gani 2000, 'Developing expatriates for the Asia-Pacific region: A comparative analysis of multinational enterprise managers from five countries across three countries', Human Resource Development Quarterly, Vol.11, No.3, pp213-235.

Adler, N.J. 1984, 'Woman in international management: where are they?', California Management Review, Vol.26, No.4, pp.78-89.

Adler, N. and Bartholomew, S. 1992, 'Managing Globally Competent People', Academy of Management Executive, Vol. 6: pp.52-65. 
Adler, N. 1986, 'International Dimensions of Organizational Behavior', Boston, Kent.

Anderson, J.C., Milkovich, G.T. and Tsui, A. 1981, 'A model of intra-organizational mobility'. Academy of Management Review, Vol.6, pp.529-538.

Bhagat, R.S. 1983, 'Effects of stressful life events on individual performance effectiveness and work adjustment process within organizational settings: a research model', Academy of Management Review, Vol.8, No.4, pp. 660-671.

Bhagat, R.S. and Prien, K.O. 1996, 'Cross-cultural training in organizational contexts', In Landis, D. and Bhagat, R.S. (Eds), Handbook of International Training, pp.216-230.

Black, J.S. 1988, 'Work role transitions: a study of American expatriate managers in Japan', Journal of International Business Studies, Vol.19: pp.277-294.

Black, J.S. and Gregersen, H.B. 1991, 'The other half of the picture: Antecedents to cross-cultural adjustment for expatriates in Pacific Rim assignments', Journal of International Business Studies, Vol. 22, No.3, pp.461-477.

Black, J.S. and Mendenhall, M. 1990, 'Cross-cultural training effectiveness: A review and a theoretical framework for future research'. Academy of Management Review, Vol.15, No.1, pp.113-136.

Black, J.S. and Mendenhall, M. 1991, (a) 'The U-curve adjustment hypothesis: A review and theoretical framework', Journal of International Business Studies, Vol.2, pp.225-247.

Black, J.S., Mendenhall, M. and Oddou, G.R. 1991, (b) 'Towards a comprehensive model of international adjustment: An integration of multiple theoretical perspectives', Academy of Management Review, Vol.16, No.2, pp. 291-317.

Black, J. S., Mendenhall, M.E. and Gregersen, H.B. 1992, Global Assignment: Successfully Expatriating and Repatriating International Managers, Jossey-Bass, San Francisco, CA.

Black, J. S. and Stephens, G. K. 1989, 'The Influence of the Spouse on American Expatriate Adjustment in Overseas Assignments', Journal of Management, Vol.15, pp.529-544.

Bochner, S., Hutnik, N. and Furnham, A. 1986, 'The friendship patterns of overseas students and host students in an Oxford student resident hall', Journal of Social Psychology, Vol.125, pp.689-694.

Bochner, S. and McLeod, B. I, Lin. 1971, 'Friendship patterns of overseas students: a functional model', International Journal of Psychology, Vol.12, pp.277-294.

Boyacigiller, N. 1990, 'The Role of Expatriates in the Management of Interdependence, Complexity and Risk in Multinational Corporations', Journal of International Business Studies, Vol.21, No.3, pp.357-381.

Brein, M. and David, K.H. 1971, 'Intercultural communication and adjustment of the sojourner', Psychological Bulletin, Vol.76, pp.215-230.

Brett. J.M., Stroh, L.K. and Reilly, A.H. 1990, 'Impact of societal and corporate changes on employee relocation', Employee Relocation Council, Washington.

Brett. J.M., Stroh, L.K. and Reilly, A.H. 1992, 'What is it like being a dual career manager in the 1990s?', Work and Family, Jossey Bass, San Francisco.

Brett. J.M. and Stroh, L.K. 1995, 'Willingness to relocate internationally', Human Resource Management, Vol.34, pp. 405-424.

Chan, W.T. 1963, A Source Book in Chinese Philosophy, Princeton University Press, Princeton, N.J.

Church, A.T. 1982, 'Sojourner adjustment', Psychological Bulletin, Vol.9, pp. 540-572.

Dowling, P.J., Welch, D.E. and Schuler, R.S. 1999, International Human Resource Management, South-Western.

Dowling, P., Schuler, R. and Welch, D. 1994, 'International Dimensions of Human Resource Management', 2nd edn, Wadsworth, California.

Edstrom, A. and Galbraith, J. 1977, 'Transfer of Managers as a Coordination and Control Strategy in Multinational Organizations', Administrative Science Quarterly, Vol.22, pp.248-263.

Fang, T. 1999, ChineseBusiness Negotiating Style, Sage Publications, Thousands Oaks.

Fieldman, D.C. and Thomas, D.C. 1992, 'Career management issues facing expatriates', Journal of International Business, Vol.23, No.2, pp.271-293.

Harris, P. and Moran, R. 1989, Managing Cultural Differences, Gulf ,Houston, Tex.

Harvey, M.G. 1985, 'The executive family: an overlooked variable in international assignment', Columbia Journal of World Business, Vol.20, pp.84-92. 
Harvey, M.G. 1995, 'Addressing the dual-career expatriation dilemma', Human Resource Planning, Vol.19, No.4, pp.18-39.

Harvey, M.G. 1996, 'The impact of dual-career families on international relocations', Human Resource Management Review, Vol.5, No.3.

Harvey, M.G. 1997, 'Dual-career expatriates: expectations, adjustment and satisfaction with international relocation', Journal of International Business Studies, Vol.27, pp.627-658.

Harvey, M.G. 1997, 'The impact of the dual-career expatriate on international relocation: the trailing spouse', International Journal of Human Resource Management.

Harvey, M.G. 1998, 'Dual-career couples during international relocation: the trailing spouse', International Journal of Human Resource Management, Vol.9, No.2, pp.309-331.

Hays, RD., 1971, 'Ascribed behavioral determinants of success-failure among U.S. expatriate managers', Journal of International Business, Vol.2, pp.40-46.

Heckhausen, J. and Krueger, J. 1993, 'Developmental expectations for the self and most other people: age grading in three functions of social comparison', Developmental Psychology, Vol.29, No.3, pp.539-547.

Kobrin, S. 1988, 'Expatriate Reduction and Strategic Control in American Multinational Corporations', Human Resource Management, Vol.27, pp.63-75.

Lee, H.W. 2002, A study of Taiwanese banking expatriates in the United States, Published dissertation of University of Idaho.

Markham, W.T., Joseph, H. and Pleck, 1986, 'Sex and willingness to move for occupational advancement: some national sample results', The Sociological Quarterly, Vol.27, No.1, pp.121-143.

Markham, W.T., Macken, P.O., Bonjean, C.M. and Corder, J. 1983, 'A note on sex, geographic mobility, and career advancement', Social Forrest, Vol.61, pp. 1138-1146.

McEnery, J. and DesHarnais, G. 1990, 'Culture Shock', Training and Development Journal, Vol.44, No.4, pp.43-47.

Mendenhall, M.E. and Oddou, G. 1985, 'The dimensions of expatriate acculturation: A review', Academy of Management Review, Vol.10, pp.39-47.

Mendenhall, M.E. and Oddou, G. 1988, 'The overseas assignment: A practical look', Business Horizons, Vol.31, No.5, pp.78-84.

Mendenhall, M.E., Dunbar, E. and Oddou, G. 1987, 'Expatriate selection, training and career-pathing: A review and critique', Human Resource management, Vol.26, No.3, pp.331-345.

Ministry of Economic Affairs (MOEA) (1997), The Investigation Report on the Outward Investment by Manufacturing Industry (in Chinese), Taiwan.

---- (1998), The Investigation Report on the Outward Investment by Manufacturing Industry (in Chinese).

---- (1999), 'Table A-12 The Growth Rate of the Industrial Output in Major Countries' (in Chinese), http://www.moea.gov.tw/ meco/stat/four/a-12.htm.

--- (2000), 'The Role of Service Industry in Economic Development' (in Chinese), http://www.moea.gov.tw/ meco/paper/issue/15.htm.

Ministry of Finance (MoF) (Taiwan) (1993), Report on the Characteristic Classifications of Tradeable Commodities.

---- (1998), Monthly Statistics of Exports and Imports, December 1998.

Ondrack, D. 1985, 'International Transfers of Managers in North American and European MNEs', Journal of International Business Studies, Vol.16, pp.1-19.

Osland, J.S. 1995, 'Working Abroad: A hero's adventure', Training and Development Journal, Vol.49, No.11, pp.47-51.

Pinder, C.C. and Das, H. 1979, 'Hidden costs and benefits of employee transfers', Human Resource Planning, Vol.2, pp.135-145.

Pinder, C. and Klaus, G. 1987, 'Time to proficiency following transfers', Academy of Management Journal, Vol.30, pp.336-353.

Schuler, R., Fulkerson, J., and Dowling, P. 1991, 'Strategic Performance Measurement and Management in Multinational Corporations', Human Resource Management, Vol.30, pp.365-392. 
Searle, W. and Ward, C. 1990, 'The prediction of psychological and socio-cultural adjustment during cross-cultural transitions', International Journal of Intercultural Relations, Vol.14, pp.449-464.

Stening, B.W. 1979, 'Problems of cross-cultural contact: A literature review', International Journal of International Relations, Vol.3, pp.269-313.

Strohl, L.L. and Caligiuri, P.M. 1998, 'Strategic human resources: a new source for competitive advantage in the global arena', International Journal of Human Resource Management, Vol.9, pp.1-17.

Tung, R.L. 1981, Selection and Training of Personnel for Overseas Assignment, Ballinger Publishing, Cambridge, MA:.

Tung, R. 1982, 'Selection and Training Procedures of U.S., European and Japanese Multinationals', California Management Review, Vol.25, pp.57-71.

Tung, R.L. and Miller, E.L. 1990, 'Managing in the twenty-first century: The need for global orientation', Management International Review, Vol.30, pp.5-18.

Van Lange, P.A.M., Otten, W., De Bruin, E.M.N. and Joireman, J.A. 1997, 'Development of prosocial, individualistic, and competitive orientations: theory and preliminary evidence', Journal of Personality and Social Psychology, Vol.73, No.4, pp.733-746.

Wederspahn, G. M. 1992, 'Costing failures in expatriate human resources management', Human Resource Planning, Vol.15, pp.27-35.

Westwood, R.I., Leung, S.M. 1994, 'The female expatriate manager experience: coping with gender and culture', International Studies of Management and Organization, Vol.24, pp.64-85.

Worm, V. 1997, Vikings and Mandarins: Sino-Scandinavian business co-operation in cross-cultural settings, Copenhagen Business School Press, Copenhagen. 